\title{
Three methods for avoiding the impacts of incompatible site index and height prediction models demonstrated on jack pine curves for Ontario
}

\author{
by C.E. Rose ${ }^{1}$, C.J. Cieszewski ${ }^{2}$ and W.H. Carmean ${ }^{3}$
}

\begin{abstract}
Fixed base-age site indices are commonly used as a covariate in height prediction models, whereby separate site index prediction equations are used with measured age and height to predict the site index when it is unknown. In such systems, a bias may result in the height prediction if the site index equation is incompatible with the height equation. We demonstrated such bias using as an example recently published models for jack pine in northern Ontario with incompatible site index and height equations. Then we offered solutions that reduce the bias in height predictions assuming that the primary objective was to predict height. First, we re-estimated the site index equation parameters using both the site index and height equations as a common prediction system and holding the published height equation parameters constant while minimizing errors in height predictions. This substantially reduced the incompatibility between the site index and the height equations. Second, we demonstrated the use of two dynamic equations as alternatives to the fixed base-age equations. Even using an irrelevant dynamic equation for another species substantially reduced the bias in short-term jack pine height projections. However, the dynamic equation fit to the jack pine height model was the most effective in reducing the bias for height projections relative to all other considered solutions and produced the least biased, most parsimonious, and most flexible solution.
\end{abstract}

Key words: incompatible site index and height equations, fixed base age equations, dynamic equations

L'indice de station reposant sur l'âge est couramment utilisé en tant que co-variable dans les modèles de prédiction de la hauteur, alors que les équations individuelles de prédiction de l'indice de station sont utilisées avec l'âge mesuré et la hauteur pour prédire l'indice de station lorsqu'il est inconnu. Dans de tels systèmes, un biais peut survenir dans la prédiction de la hauteur si l'équation de l'indice de station est incompatible avec l'équation de hauteur. Nous avons démontré un tel biais à titre d'exemple à partir de modèles publiés récemment pour le pin gris du nord de l'Ontario et d'indice de station ainsi que d'équations de hauteur incompatibles. Nous avons présenté par la suite des solutions qui réduisent le biais dans les prédictions de hauteur en assumant que l'objectif principal était de prédire la hauteur. En premier lieu, nous avons estimé de nouveau les paramètres de l'équation de l'indice de station au moyen de l'indice de site et des équations de hauteurs en tant que système commun de prédiction et en conservant les paramètres des équations de hauteurs publiées de façon constante tout en minimisant les erreurs dans les prédictions de hauteur. Cette procédure a réduit substantiellement l'incompatibilité entre l'indice de station et les équations de hauteurs. En second lieu, nous avons démontré l'utilisation de deux équations dynamiques en tant alternatives aux équations reposant sur un âge donné. Même en utilisant une équation dynamique n'ayant aucun lien avec l'espèce, le biais a été réduit substantiellement dans les projections à court terme de la hauteur du pin gris. Cependant, l'équation dynamique conçue pour le modèle de hauteur du pin gris a été la plus efficace pour réduire le biais dans les projections de hauteurs comparativement à toutes les autres solutions envisagées et a produit la solution la moins biaisée, la plus parcimonieuse et la plus flexible.

Mots-clés: équations incompatibles d'indice de station et de hauteur, équations à âge donné, équations dynamiques

\section{Introduction}

The ability to accurately project heights is a crucial component of the forestry decision process. Site-dependent height growth equations and other similar self-referencing functions (Northway 1985) are important in forest management growth and yield predictions. When the height equation cannot be inverted, i.e., a closed form solution for the site index (SI) as a

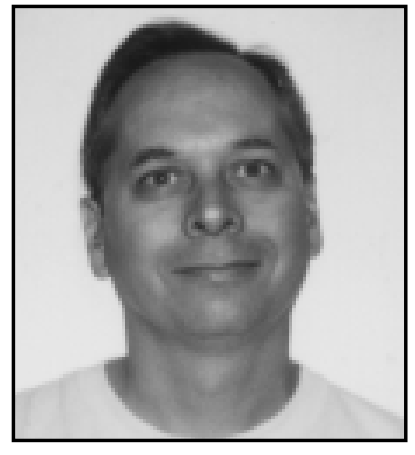

C.E. Rose

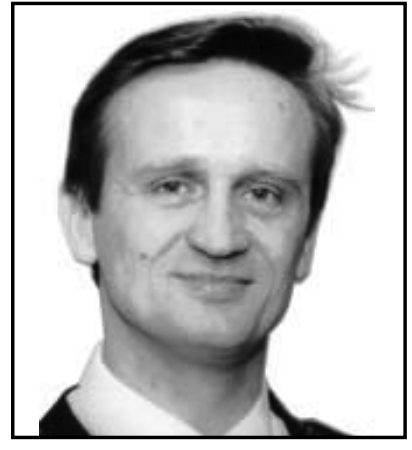

C.J. Cieszewski

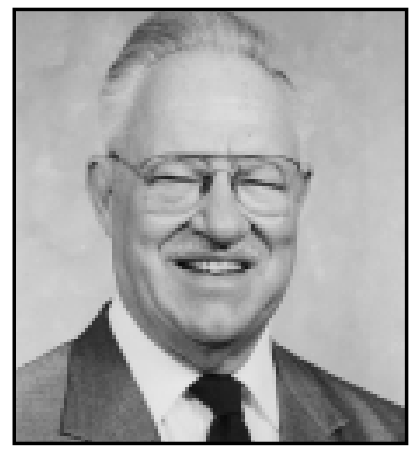

W.H. Carmean function of height and age cannot be obtained, the site indices

\footnotetext{
${ }^{1}$ Mathematical Statistician, Centers for Disease Control and Prevention, Division of Bacterial and Mycotic Diseases/NCID, 1600 Clifton Rd., Mailstop C09, Atlanta, GA 30333, U.S.A. E-mail: cvr7@cdc.gov

${ }^{2}$ Associate Professor, Fiber Supply Assessment, D.B. Warnell School of Forest Resources, The University of Georgia, Athens, GA 30602, U.S.A. Email: http://growthandyield.com/chris

${ }^{3}$ Professor Emeritus, Faculty of Forestry and the Forest Environment, Lakehead University, Thunder Bay, ON P7B 5E1. E-mail: sdunning@sky.lakeheadu.ca
}

are usually estimated using iterative procedures or through independent SI prediction equations. Using an iterative algorithm to solve for SI given a height and age (e.g., Biging and Wensel 1985, Shaw and Packee 1998) assumes that the appropriate SI is the one that corresponds to the SI curve passing through the given height and age. Conversely, using an independent equation for SI predictions assumes that the SI does not have to belong to the same curve. Many studies have developed separate SI and height prediction equations (e.g., 
Curtis et al. 1974, Monserud 1984, Golden et al. 1988, Carmean et al. 2001). In these types of systems, one equation is used to estimate SI as a function of a known height and age, and another equation is used to estimate height as a function of SI and age. Using separate height and SI equations results in incompatible estimates of SI and height predictions.

Equations formulated for height estimation can be classified as static or dynamic (Cieszewski 2001). Static height equations use a fixed base age SI and are the most widely used for modelling height in forestry. Dynamic equations are capable of using variable base ages. When based on proper algebra, dynamic equations are base age invariant (Bailey and Clutter 1974) so selection of any arbitrary base age in these equations has no effect on their height predictions. One desirable property for height equations is that height predictions closely follow the actual height growth pattern with no declining heights for any prediction period. It is possible when using a system of incompatible height and SI equations that the projected heights using the height equation and estimated SI from the SI equation may produce decreasing height predictions, even when the height and SI functions are strictly increasing. This phenomenon can occur because the estimated SI (from the incompatible SI equation) can be smaller than the height at base age in the height equation that is implied by given height and age information.

Our objective is to propose compensating methods for incompatible SI and height equations that reduce or eliminate the incompatibility. Our examples use the jack pine (Pinus banksiana Lamb.) system of incompatible site index and height models described in Carmean et al. (2001). We propose for this system improved equations that result in a substantial bias reduction for height predictions.

\section{Methods}

We demonstrated the incompatibility of separate SI and height equations by predicting site indices from known heights and ages and then used the predicted site indices to predict height at the known ages. We then compared these predicted heights with the known heights at the same ages. The data were generated using incompatible SI and height equations by Carmean et al. (2001), who presented independent SI and height prediction equations for jack pine in Ontario. Observed jack pine site indices for their study ranged from $7.6 \mathrm{~m}$ to $22.4 \mathrm{~m}$. with an average of about $16.3 \mathrm{~m}$ and the oldest plots were 157 years. Their height equation is:

$$
H=1.3+a_{1}(S-1.3)^{b_{1}}\left(1-K^{\frac{A}{50}}\right)^{c_{1}(S-1.3)^{d_{1}}}
$$

where

$$
K=1-\left(\frac{S-1.3}{a_{1}(S-1.3)^{b_{1}}}\right)^{\frac{1}{c_{1}(S-1.3)^{d_{1}}}}
$$

$H$ is mean dominant height, $A$ is age at breast height, $S$ is site index (base age 50 years at breast height), $a_{1}=4.1459, b_{1}=0.6224$, $c_{1}=1.3723$, and $d_{1}=-0.0802$. Equation (1) is not solvable for SI, so Carmean et al. (2001) presented a separate SI prediction equation:

$$
\begin{aligned}
S= & a_{2}+b_{2} H+c_{2} \ln (H)+d_{2} \ln (A)+e_{2} \ln (A)^{2} \\
& +f_{2}\left(\frac{H}{A}\right)+g_{2} A \ln (H)
\end{aligned}
$$

where $a_{2}=13.144, b_{2}=0.405, c_{2}=7.4013, d_{2}=-2.4941$, $e_{2}=-1.1382, f_{2}=-0.00185$, and $g_{2}=0.024$. We analyzed the consequences of using SI equation (2) predictions as explanatory variables in height equation (1) under several scenarios. First, equation (2) was used to predict site indices from heights of $4.0 \mathrm{~m}, 12.0 \mathrm{~m}$, and $15.0 \mathrm{~m}$ at age 20 . These predicted site indices were used in equation (1) to project heights from age 15 to 50 . Next, site indices were estimated using equation (2) from heights of $10.0-40.0 \mathrm{~m}$ ( $1.0 \mathrm{~m}$ increments) at age 100 . These predicted site indices were used in equation (1) to project yearly heights to age 150 . Lastly, we compared actual site indices of $5.0-30.0 \mathrm{~m}$ ( $1.0 \mathrm{~m}$ increments) to age 50 predicted site indices using equation (1). These scenarios demonstrated the possible effects of using predicted site indices from equation (2) in height equation (1).

After assessing the effect of using equation (1) with equation (2), we offered several alternative methods reducing the bias in height predictions when using equations (1) and (2). We assumed that the primary objective was to predict height. For our first approach, to reduce the incompatibility of SI equation (2) with height equation (1), we re-estimated the parameters of equation (2) to minimize errors in height predictions while holding the estimated parameters for equation (1) constant. The errors for equation (2) were minimized with respect to height by substituting equation (2) into equation (1), i.e.,

$$
H=1.3+a_{1}\left(S^{\prime}\right)^{b_{1}}\left(1-K^{\frac{A}{50}}\right)^{c_{1}\left(S^{\prime}-1.3\right)^{d_{1}}}
$$

where

$$
K=1-\left(\frac{S^{\prime}-1.3}{a_{1}\left(S^{\prime}-1.3\right)^{b_{1}}}\right) \frac{1}{c_{1}\left(S^{\prime}-1.3\right)^{d_{1}}}
$$

and

$$
\begin{aligned}
S^{\prime}= & a_{3}+b_{3} H+c_{3} \ln (H)+d_{3} \ln (A)+e_{3} \ln (A)^{2} \\
& +f_{3}\left(\frac{H}{A}\right)+g_{3} A \ln (H)
\end{aligned}
$$

is the site index equation, $a_{3}=-4.3101, b_{3}=0.6752, c_{3}=-2.2446$, $d_{3}=7.1776, e_{3}=-1.4397, f_{3}=21.6874, g_{3}=0.01956$, and all other terms are previously defined. We used the height data $\left(\mathrm{H}_{\mathrm{t}(1)}\right)$, which we generated from height equation (1) using site indices $8.0-22.0 \mathrm{~m}$ ( $1.0 \mathrm{~m}$ increments) and ages $20-100$ years (5-year increments), to re-estimate the parameters of SI equation (2),

We assessed site index equations (2) and (3) and their respective compatibility with height equation (1) by predicting site indices from equations (2) and (3) using the $\mathrm{H}_{\mathrm{t}(1)}$ 
data. Then we used these predicted site indices to predict their corresponding heights $\left(\mathrm{H}_{\mathrm{t}(1)}^{\prime}\right)$ using equation (1). If $\mathrm{H}_{\mathrm{t}(1)}=$ $\mathrm{H}_{\mathrm{t}(1)}^{\prime}$, then there was no incompatibility and the bias was zero; however, non-zero bias was expected due to the incompatibility between height equation (1) and SI equations (2) and (3). The incompatibility of equations (2) and (3) with equation (1) was quantified by computing the mean deviation, mean absolute deviation, error sums of squares (SSE), and standard deviation (RMSE) using $\mathrm{H}_{\mathrm{t}(1)}$ and $\mathrm{H}_{\mathrm{t}(1)}^{\prime}$. Furthermore, to assess the impact on height predictions when choosing different height-age combinations for SI prediction we used a subset of the $\mathrm{H}_{\mathrm{t}(1)}$ data, ages 20 to100 years (5-year increments) for low and high site indices (10.0 and $20.0 \mathrm{~m}$ ). This subset was treated as measurement records and used to estimate the site indices from equations (2) and (3). We used these predicted site indices in equation (1) to predict the heights $\left(\mathrm{H}_{\mathrm{t}(2)}\right)$ at their respective age and then we calculated the height bias as $\mathrm{H}_{\mathrm{t}(1)}-\mathrm{H}_{\mathrm{t}(2)}$.

Our next approach applied arbitrarily a lodgepole pine dynamic equation for Alberta (Cieszewski and Bella 1989),

$$
H=\frac{h_{0}+a_{4}+k}{2+\frac{b_{4} A^{-1-c_{4}}}{h_{0}-a_{4}+k}}
$$

where

$$
k=\sqrt{\left(h_{0}-a_{4}\right)^{2}+b_{4} h_{0} A_{0}^{-1-c_{4}}}
$$

and $h_{0}$ is the reference height at any age $A_{0}, A$ is the prediction age, $a_{4}=17.7663$, and $b_{4}=8045.28$. The rational for using this approach was that we wanted to see to what extent the benefits of using a dynamic equation would compensate for the disadvantage of using an irrelevant model. By definition, the height prediction bias is zero for dynamic models when $A=A_{0}$. Hence, equation (4) will always outperform SI equations (2) and (3) when used with equation (1), i.e., there is no incompatibility for dynamic equations. However, the performance of dynamic equation (4) is uncertain for short-term height projections.

Our final approach used the height data $\mathrm{H}_{\mathrm{t}(1)}$ to fit the dynamic equation (Cieszewski 2001) of:

$$
H=h_{0}\left(\frac{A}{A_{0}}\right)^{a_{5}+b_{5}}\left(\frac{A_{0}^{b_{5}} z_{5}+d_{5}}{A^{b_{5}} z_{5}+d_{5}}\right)
$$

where

$$
z_{5}=f_{5}+\left(f_{5}^{2}+\frac{2 d_{5} h_{0}}{A_{0}^{a_{5}+b_{5}}}\right)^{\frac{1}{2}} \text { and } f_{5}=\left(\frac{h_{0}}{A_{0}^{a_{5}}}-g_{5}\right)
$$

and all other terms are as previously defined. The parameters were fitted using the dummy variable approach described in Cieszewski et al. (2000). This approach treats the site indices as nuisance parameters, or local parameters, while estimating the model parameters as global parameters, thereby not forcing the curve through an arbitrary reference point. The estimated global parameters were $a_{5}=-0.5946, b_{5}=1.416274, d_{5}=$ 399325.39 , and $f_{5}=589.8711$.

We compared models using simulation to demonstrate the effect of using SI equations (2) and (3) with equation (1), as well as the dynamic equations (4) and (5) for height projections. Site indices were chosen from $8.0 \mathrm{~m}$ to $22.0 \mathrm{~m}$ by $2.0 \mathrm{~m}$ increments, and initial age was randomly selected between 5 and 20 years. We selected six additional current age classes by adding 20,40,60, 80, 100, and 120 years to the randomly selected age. Then heights are predicted for each of the current age and SI classes and projected for 1, 5, and 10 years using equation (1). These predicted and projected heights are treated as true heights $\left(\mathrm{H}_{\mathrm{t}}\right)$. We then predicted site indices for each height and age class using equations (2) and (3). These predicted site indices are then used in equation (1) to project heights 1 , 5 , and 10 years for each of the current age and SI combinations. Dynamic equations (4) and (5) projected the initial heights 1 , 5 , and 10 years using the predicted heights $\left(\mathrm{H}_{\mathrm{t}}\right)$ from equation (1). Finally, these projected heights are compared with the actual heights $\left(\mathrm{H}_{\mathrm{t}}\right)$. We evaluated model performance by comparing the mean deviation, mean absolute deviation, and SSE for the 1-, 5-, and 10-year height projections.

\section{Results}

Substantial height prediction bias can result when using the site indices predicted from SI equation (2) in height equation (1). For the age 20 height data, predicted heights at age 21 were generally less than the actual height at age 20 . Height predictions generated using site indices estimated from age 100 height data revealed that height predictions using equation (2) SI predictions decline in height from age 100 to 101 (Fig. 1a) except for the $19.0 \mathrm{~m}$ and $20.0 \mathrm{~m}$ heights. The predicted SI only equalled the actual height at age 50 for two heights (Fig. 2b), which illustrates that substantial bias can result when using equations (1) and (2) as a system. Equation (2) predicted SI was equal to the actual SI only when the SI was approximately $10.7 \mathrm{~m}$ or $19.0 \mathrm{~m}$.

As an example of the bias, which can result when using equation (2) with equation (1), suppose the actual height at age 50 height is $16.0 \mathrm{~m}$, then the resulting SI using equation (2) is $16.3 \mathrm{~m}$. At the data extremes, the equation (2) bias is approximately $-1.5 \mathrm{~m}$ and $-0.5 \mathrm{~m}$ for the base age 50 years site indices of $7.6 \mathrm{~m}$ and $22.4 \mathrm{~m}$, respectively. It is this underestimation of the true SI by equation (2) that caused the decreasing heights for short-term projections.

Equation (3) substantially reduced the incompatibility between the height and SI equations. Using equation (3) with equation (1) instead of equation (2) reduced the height prediction bias from 0.2560 to $-0.0002753 \mathrm{~m}$., for our example. The $\mathrm{H}_{\mathrm{t}(1)}$ $-\mathrm{H}_{\mathrm{t}(2)}$ mean absolute deviation and SSE when using equation (2) were $0.4278 \mathrm{~m}$. and 52.25 , whereas with equation (3) they were $0.1278 \mathrm{~m}$. and 3.52 . Similarly, the root mean square error was reduced from $0.6364 \mathrm{~m}$. to $0.1652 \mathrm{~m}$. and the mean deviation and mean absolute deviation by SI class were substantially smaller (Fig. 2).

The choice of height-age combination used to predict site index can have a drastic effect on the height prediction bias (Fig. $3)$. Height-age curves generated using a SI of $10.0 \mathrm{~m}$ generated large bias when using equation (2) with equation (1). The predicted height-age curves using equation (2) with equation (1) for a $20.0 \mathrm{~m}$ SI produced severe underestimations in all con- 


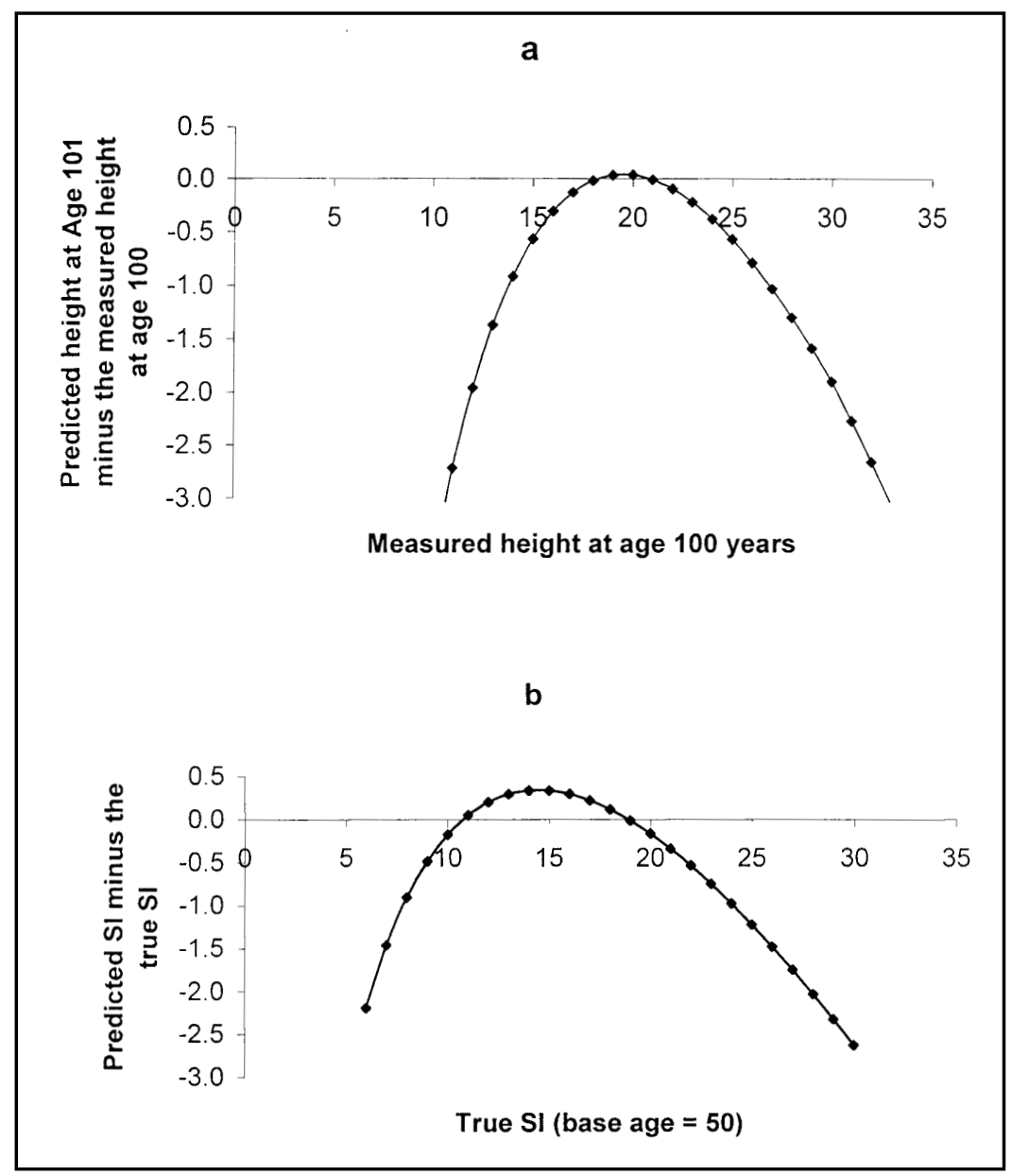

Fig.1. The age 101 projected bias that resulted from predicting the site index using measured breast height age 100 stands and then predicting the age 101 height (a). The site index equation bias that resulted from predicting the site index given the breast height 50 height (b). These biases are a result of using equation (2) with equation (1).

sidered age classes. Generated height-age curves and the corresponding bias using equation (3) with equation (1) were substantially improved. Fig. 4 illustrates predicted heights at various ages and their corresponding biases given site indices of $10.0 \mathrm{~m}$ and $20.0 \mathrm{~m}$ when using equations (2) and (3) with equation (1). For a SI of $10.0 \mathrm{~m}$, the predicted heights using equation (2) were overestimated and underestimated when using young and older measurement ages, respectively. For a SI of $20.0 \mathrm{~m}$, equation (2) height predictions were substantially underestimated. Equation (3) predicted heights were similar and the corresponding bias for both site indices was negligible. The largest absolute bias for equation (3) was approximately 0.15 $\mathrm{m}$ for the $20.0 \mathrm{~m}$ SI class, whereas for equation (2) it was about $0.80 \mathrm{~m}$.

1- and 10-year height projection biases for equations (2) and (3) when used with equation (1) and dynamic equations (4) and (5) are illustrated in Fig. 5. Equation (2) performs poorly relative to the other equations. Equation (3) substantially reduced the bias for 1- and 10-year height projections relative to equation (2). Moreover, dynamic equation (4), which was developed for lodgepole pine and exhibits systematic bias, performed better than equation (3) for the 1-year and about equally for the 10 -year height predictions. Dynamic equation (5) had substantially less bias for all the age classes relative to the other equations. Furthermore, it performed substantially better than the other equations using the mean error, mean absolute error, and SSE criteria (Table 1). Dynamic equation (5) reduced the SSE for the 1-, 5-, and 10-year height projections by almost 3000, 187, and 69 times, respectively from SI equation (2) when used with height equation (1).

\section{Discussion}

The assessment of using equation (2) with equation (1) revealed that it is possible that the resulting height predictions will decline from the actual heights. These declining height predictions are a direct result of the incompatibility between equations (1) and (2). Moreover, the predicted height decline when using a predicted SI in the height equation is not necessarily inconsequential.

Equation (3) parameters were estimated by minimizing the errors with respect to height, which resulted in a substantial reduction in the incompatibility of equations (1) and (3) relative to equation (2) with (1). For example, the SSE was reduced when using equation (3) instead of equation (2) from 52.25 to 3.52. In practical terms, for our example, equation (2) resulted in a standard deviation of over $0.64 \mathrm{~m}$, whereas equation (3) 


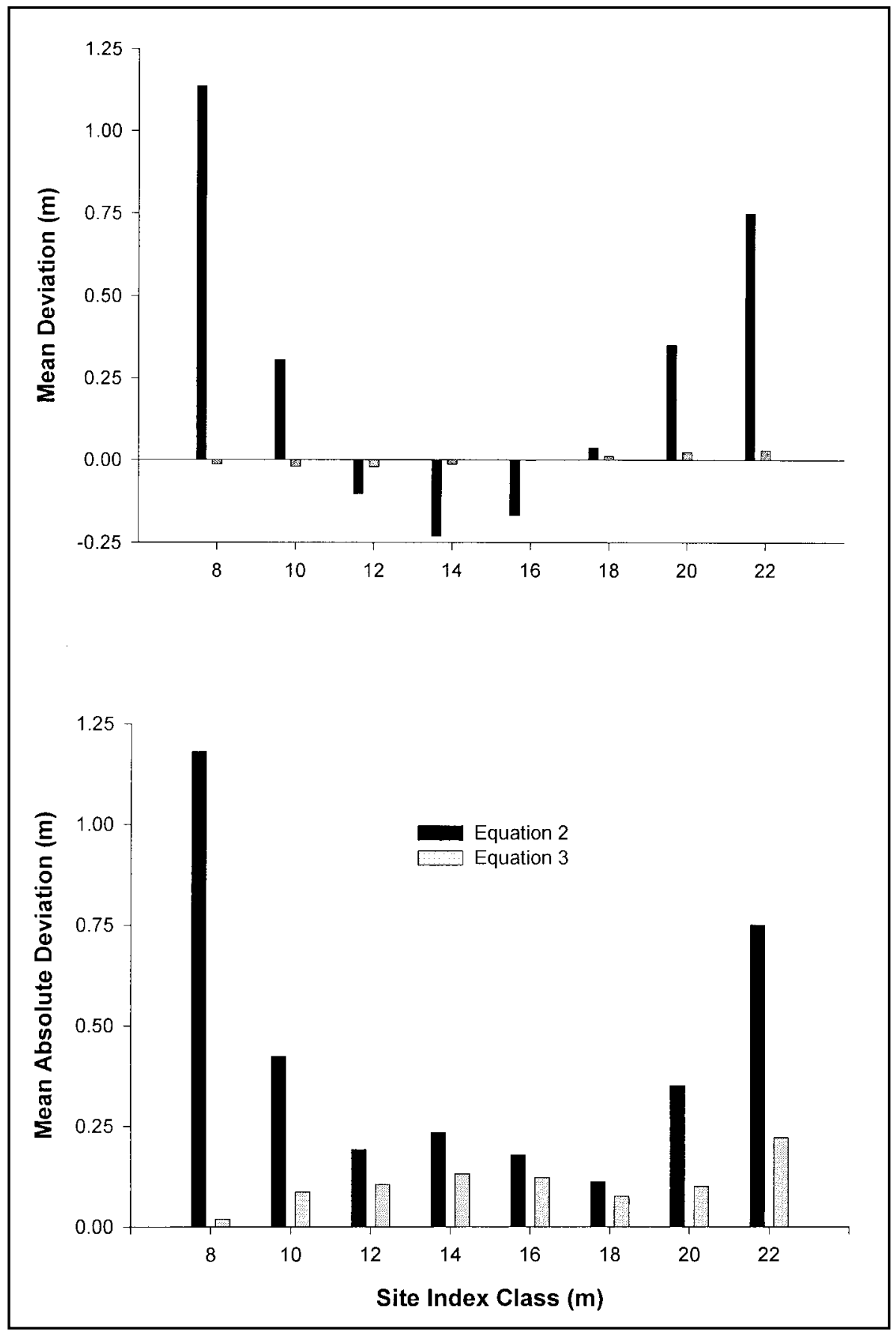

Fig. 2. The mean deviation and mean absolute deviation by site index class using site index equations (2) and (3) with height equation (1).

resulted in a standard deviation of approximately $0.17 \mathrm{~m}$. In addition, for equations (2) and (3), the predicted SI, given a heightage combination generated from the height equation, were not usually relevant to the height-age combination from which they were estimated. If the predicted site indices were relevant, then the heights predicted using the height equation with the predicted site indices and base age would equal the actual values. In addition, the bias that results from predicting height using different heights and measurement ages to predict SI would be zero if they were unbiased. As illustrated when using equation (2), there was substantial bias in most of the predictions for the examples considered. Generated height-age curves using equation (3) with equation (1) illustrated that the resulting bias for the $10.0 \mathrm{~m}$ and $20.0 \mathrm{~m}$ site indices was negligible and dramatically reduced relative to equation (2) with equation (1).

Equation (2) when used with equation (1) performed poorly relative to the other models for the 1-, 5-, and 10-year height projections and equation (3) offered a substantial improvement over equation (2) when used with equation (1). However, there were still some predictions of declining heights when equation (3) is used with equation (1). By definition, dynamic equations predict the measured height with no error at the 


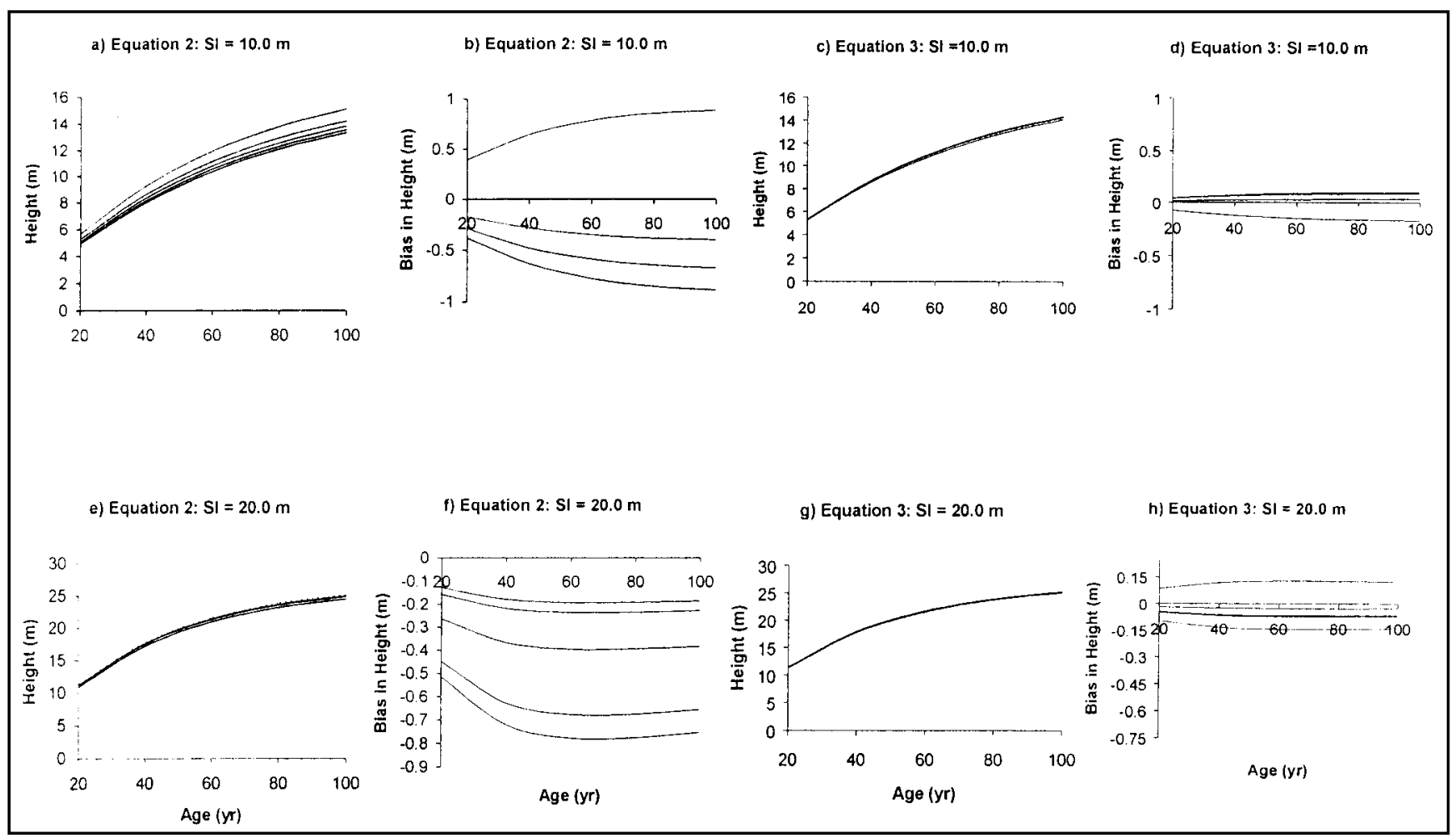

Fig. 3. An example of height-age curves generated using predicted site indices from different height-age combinations using equations (2) and (3) with equation (1) when the actual site indices are 10.0 and 20.0 meters. This illustrates the corresponding bias in height predictions that results when using different height-age combinations to predict site index, which is then used in equation (1) to predict the height.

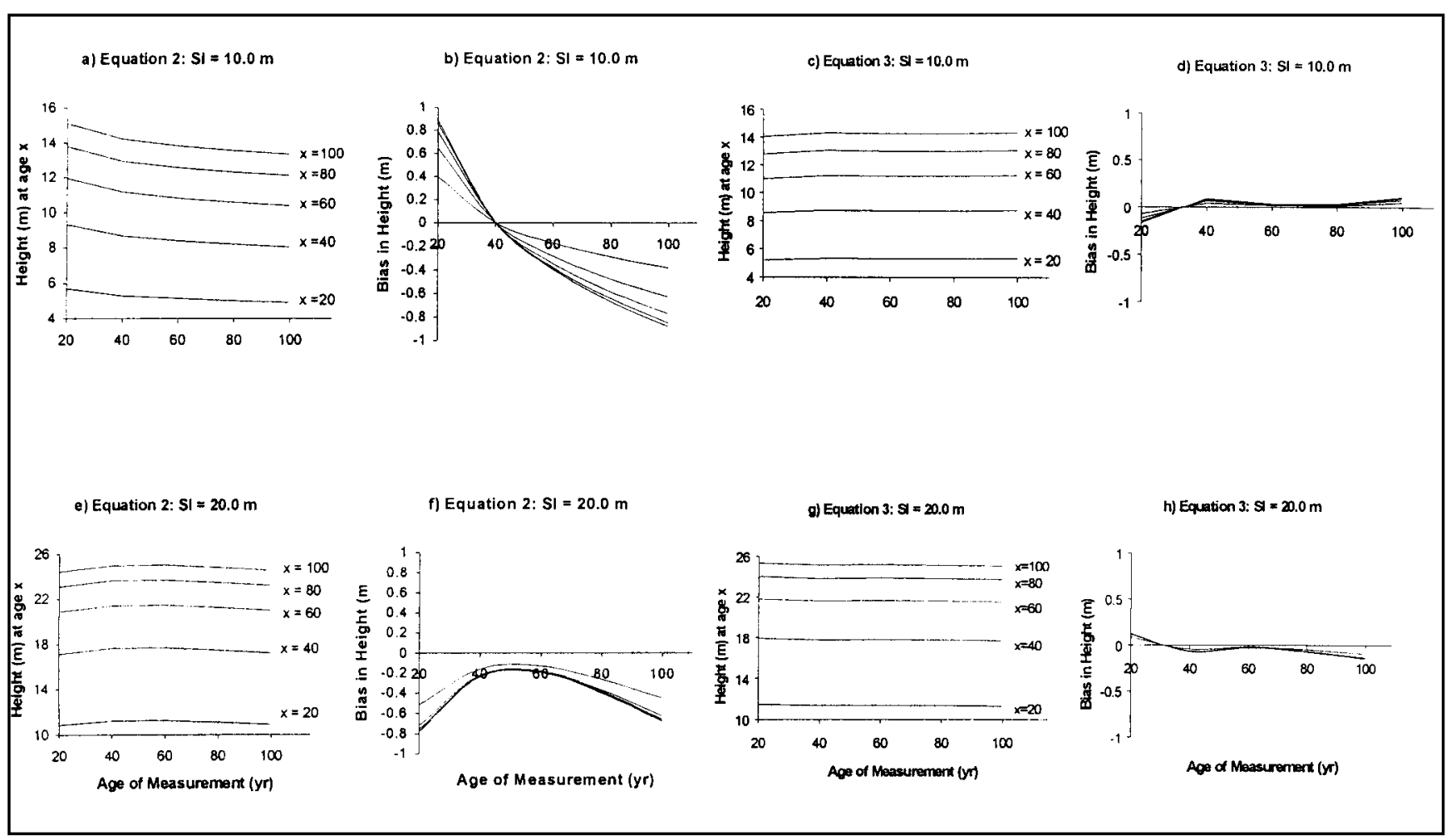

Fig. 4. Predicted site indices using equations (2) and (3) for measurement ages of 20, 40, 60, 80, and 100 years, generated from the height age curves that have site indices of 10.0 and $20.0 \mathrm{~m}$. 

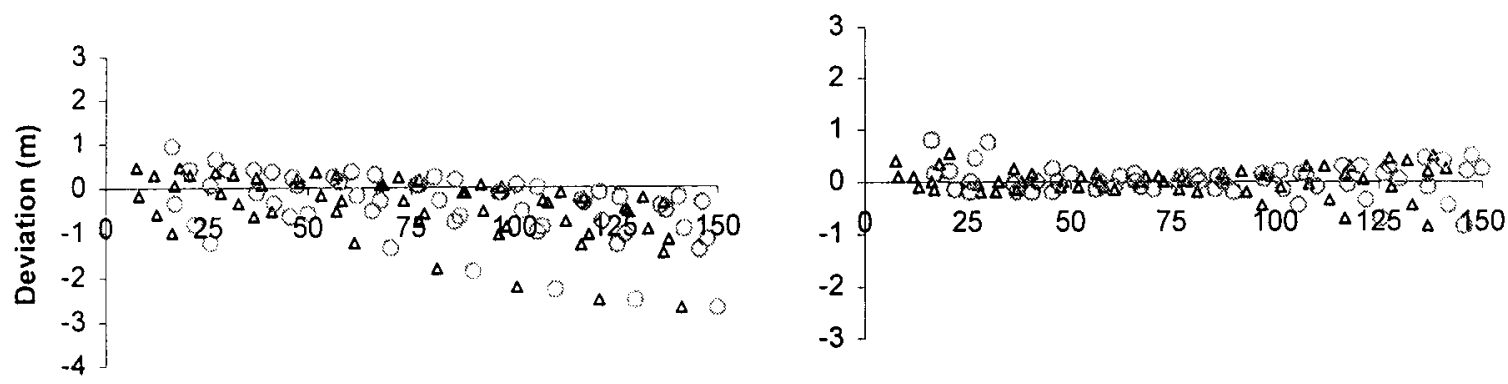

Equation 4

Equation 5
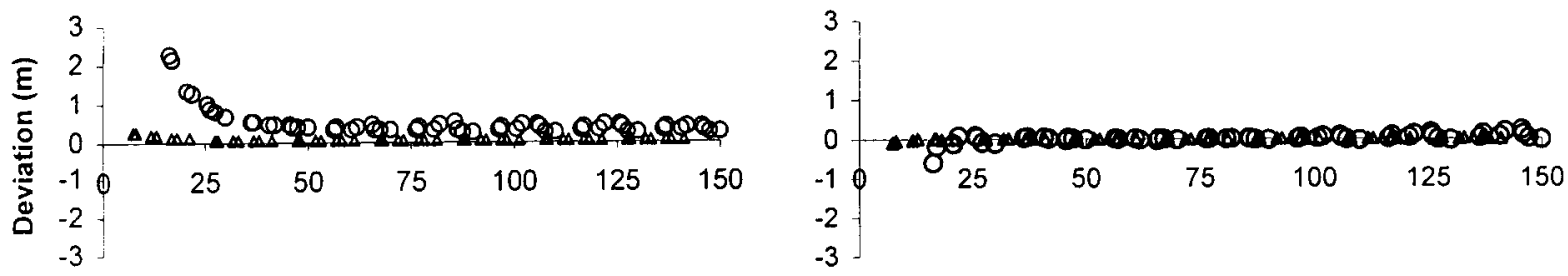

Age (yr)

Age (yr)

Fig. 5. An example of the errors in height predictions for one (triangles) and ten-year (circles) height projections using site index equations (2) and (3) with height equation (1) and dynamic equations (4) and (5).

Table 1. The 1-, 5-, and 10-year height projection summary statistics using equations (2) and (3) with equation (1), and dynamic equations (4) and (5). MD is the mean deviation, MAD is the mean absolute deviation, and SSE is the error sum of squares

\begin{tabular}{|c|c|c|c|c|}
\hline \multirow[b]{2}{*}{ Criterion } & \multicolumn{4}{|c|}{ Equations } \\
\hline & 2 & 3 & 4 & 5 \\
\hline & \multicolumn{4}{|c|}{ One-year Height Projections } \\
\hline MD & -0.4385 & 0.0226 & 0.0501 & -0.00132 \\
\hline MAD & 0.5854 & 0.1958 & 0.0501 & 0.00674 \\
\hline \multirow[t]{2}{*}{$\operatorname{SSE}^{(}$} & 39.4836 & 3.9329 & 0.2459 & 0.0132 \\
\hline & \multicolumn{4}{|c|}{ Five-year Height Projections } \\
\hline MD & -0.4378 & 0.0288 & 0.2473 & -0.00141 \\
\hline MAD & 0.6037 & 0.2047 & 0.2473 & 0.03060 \\
\hline \multirow[t]{2}{*}{ SSE } & 40.8199 & 4.3039 & 5.8876 & 0.2190 \\
\hline & \multicolumn{4}{|c|}{ Ten-year Height Projections } \\
\hline MD & -0.4362 & 0.0357 & 0.4835 & 0.00534 \\
\hline MAD & 0.6228 & 0.2144 & 0.4835 & 0.05668 \\
\hline SSE & 42.4629 & 4.8367 & 21.7502 & 0.6193 \\
\hline
\end{tabular}

measurement age. Therefore, the height projection bias for the dynamic equations is a result of the different slopes for these projection periods from height equation (1), which has minimal impact for short-term height projections. Dynamic equation (4) offered a substantial improvement over equation (2) for these short-term height projections even though it was developed for a different species. The bias exhibited by dynamic equation (4) was systematic and thus, could be easily adjusted to improve the performance of the 10-year height projections. Dynam- ic equation (5) performed substantially better relative to the other equations for these height projections. Hence, we would considerably improve the predictions by using dynamic equation (5) for short-term height projections.

In conclusion, using an incompatible system of height and SI equations can result in substantial bias. Re-estimating the SI equation parameters by minimizing the deviations relevant to the height predictions will reduce the height prediction biases. However, as long as the height and SI equations are based on 
different equations, the system remains biased. Dynamic equations are superior to fixed base-age equations based systems of incompatible equations. This superiority was demonstrated predicting Ontario jack pine heights using the irrelevant equation (4) without any adjustments of its parameters, which were estimated using lodgepole pine data from Alberta. Furthermore, the dynamic equation (5) demonstrated that it can produce predictions that are more accurate and the resulting equation was more parsimonious. Site index equation (2) and height equation (1) have a combined 11 parameters, whereas dynamic equation (5) has four parameters. Moreover, dynamic equation (5) expressed both the height and SI models in a single equation.

\section{References}

Bailey, R.L. and J.L. Clutter. 1974. Base-age invariant polymorphic site curves. For. Sci. 20: 155-159.

Biging, G.S. and L.C. Wensel. 1985. Site index equations for young-growth mixed conifers of Northern California. Northern California Yield Coop. Res. Note No. 8. University of California, Berkeley, CA.14 p.

Carmean W.H., G.P Niznowski and T.G. Hazenberg. 2001. Polymorphic site index curves for jack pine in Northern Ontario. For. Chron. 77(1): 141-150.

Cieszewski, C.J. 2001. Three methods of deriving advanced dynamic site equations demonstrated on inland Douglas-fir site curves. Can J. For. Res. 31(1): 165-173.
Cieszewski, C.J. and I.E. Bella. 1989. Polymorphic height and site index curves for lodgepole pine in Alberta. Can. J. For. Res. 19: 1151-1160.

Cieszewski, C.J., W.M. Harrison and S.W. Martin. 2000. Examples of practical methods for unbiased parameter estimation in selfreferencing functions. In C.J. Cieszewski (ed.). Proceedings of the First International Conference on Measurements and Quantitative Methods and Management and The 1999 Southern Mensurationists Meeting. D.B. Warnell School of Forest Resources. University of Georgia. Athens, GA. 207 p.

Curtis, R.O., D.J. DeMars and F.R. Herman. 1974. Which dependent variable in site index-height-age regressions? Forest Sci. 20: 74-87. Golden, M.S., R.S. Meldahl and C.L. Tuttle. 1988. Estimating natural yellow-poplar site index in the hilly coastal plain of Alabama. South. J. Appl. For. 12(1): 41-45.

Monserud, R.A. 1984. Height-growth and site index curves for inland Douglas-fir based on stem analysis data and forest habitat type. For. Sci. 30: 943-965.

Northway, S.M. 1985. Fitting site index equations and other self-referencing functions. For. Sci. 31: 233-235.

Shaw, J.D. and E.C. Packee. 1998. Site index of Balsam Poplar/Western black Cottonwood in interior and southcentral Alaska. North. J. Appl. For.15(4): 174-181. 